\title{
Clinical uses and Toxicity of Ephedra sinica: An Evidence-Based Comprehensive Retrospective Review (2004-2017)
}

\author{
Walaa Al saeed ', Marwa Al Dhamen' ${ }^{1}$, Rizwan Ahmad $^{2 *}$, Niyaz Ahmad ${ }^{3}$, Atta Abbas Naqvi ${ }^{4}$
}

\section{Walaa Al saeed', Marwa Al Dhamen', Rizwan Ah- mad $^{2 *}$, Niyaz Ahmad ${ }^{3}$, Atta Abbas Naqvi ${ }^{4}$}

'College of Clinical Pharmacy, Imam Abdulrahman Bin Faisal University, Dammam, SAUDI ARABIA.

${ }^{2}$ Natural Products and Alternative Medicines, College of Clinical Pharmacy, Imam Abdulrahman Bin Faisal University, Dammam, SAUDI ARABIA.

${ }^{3}$ Department of Pharmaceutics, College of Clinical Pharmacy, Imam Abdulrahman Bin Faisal University, SAUDI ARABIA.

${ }^{4}$ Department of Pharmacy Practice, College of Clinical Pharmacy, Imam Abdulrahman Bin Faisal University, SAUDI ARABIA.

\section{Correspondence}

Dr. Rizwan Ahmad

College of Clinical Pharmacy, Imam Abdulrahman Bin Faisal University, Dammam, Kingdom of Saudi Arabia.

Phone no : +966 549831835

E-mail: rizvistar_36@yahoo.com, rareiyadh@iau.edu.sa

\section{History}

- Submission Date: 09-09-2018;

- Review completed: 27-11-2018;

- Accepted Date: 19-12-2018

\section{DOI : 10.5530/pj.2019.11.68}

Article Available online

http://www.phcogj.com/v11/i2

\section{Copyright}

(C) 2019 Phcog.Net. This is an openaccess article distributed under the terms of the Creative Commons Attribution 4.0 International license.

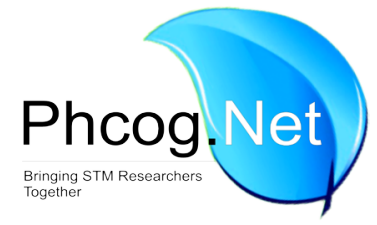

\begin{abstract}
Background: Ephedra sinica (ES) (Ma-huang) is a well-known plant due to its widespread therapeutic uses. However, many adverse effects such as hepatitis, nephritises, and cardiovascular toxicity have been reported for this plant. Few of these side effects are reversible whereas others are irreversible and may even lead to death. Aim of the Study: The aim of this study was to investigate the clinical uses and toxicity cases/consequences associated with the use of ES. The review will compare and evaluate the cases reported for ES and identify the causes which make the plant a poisonous one. Materials and Methods: An extensive literature review was conducted from 2004 to 2017, and research literature regarding the clinical cases were collected using databases and books such as Google Scholar, Science Direct, Research gate, PubMed, and Web of Science/Thomson Reuters whereas the keywords searched were "Ephedra sinica," clinical cases of Ephedra sinica, "Ma-hung poisonous," "Ma-hung toxicity reported cases and treatment," and "Ephedra Sinica toxicity reported cases and treatment." Results: eleven different cases were identified which met the eligibility criteria and were studied in detail to extract out the findings. It turned out that most of the patients and participants developed adverse side effects following the use of ES, and after a proper course of treatment or trail, some of the side effects were reversible, whereas others were found irreversible. The most common adverse effects and toxicity observed in patients were liver problems, renal failures, and cardiac toxicity which resulted in two mortalities whereas the other two got recovered. On an in-depth study, it was revealed that most of the toxicities in such cases were associated with the use of ES in combination with other conventional drugs, long-term use, or use in patients with cardiac and renal problems without a medical supervision. Conclusion: Hence, it is concluded that ES may have reversible as well as irreversible adverse effects and may even result in death; however, the use of a plant with the proper knowledge and under sound medical supervision may reduce such exaggerations. Key words: Cardiac problems, Clinical cases, Ephedra sinica, Liver problems, Toxicity
\end{abstract}

\section{INTRODUCTION}

Herbs as medicines are well known and are used since long for treating various ailments. The first ever such use for any herb has been recorded by Egyptians and Ancient Chinese in medical prescription as early as 2500 BC. ${ }^{1,2}$ The researchers found that most of the peoples are using plants in different parts of the world to treat a certain disease. ${ }^{3}$ For example, Liujunzi Tang has been used to treat Phlegm-Heat syndrome. ${ }^{4}$ Similarly, Ginkgo biloba has been used to enhance memory and circulatory diseases in various parts of the world. ${ }^{3,5}$ A plethora of plants is available where they are actively used to treat disorders such as respiratory, central nervous, and cardiovascular system diseases. ${ }^{6-8}$

Ephedra sinica (ES) is also considered as one of the most significant plants in traditional medicine. It belongs to the family Ephedraceae and known with its synonym in Korea, China, and Japan, i.e., Ma-huang. The synonym Ma-huang in Chinese literally means a "yellow hemp" or "yellow astringent" referring to its distinctive coloring. ${ }^{10}$ According to the literature, ES has been used for more than 5000 years to treat many disease, ${ }^{11}$ and traditionally, the dried stems of ES as a tea was used to treat asthma, coughs, fever, problems with urination, lack of sweating, and to alleviate edema. ${ }^{12}$ Like any other crude drug, it has an official monograph in both the Chinese and Japanese Pharmacopoeias, where it is standardized beside the main alkaloids that are analog of amphetamine: pseudoephedrine and ephedrine. ${ }^{13}$ It contains proanthocyanidins and phenylpropylamino alkaloids that are known as ephedrine alkaloids: (1S, 2S)pseudoephedrine, (1R, 2S)-ephedrine, (1S, 2S)-norpseudoephedrine, $(1 \mathrm{R}, 2 \mathrm{~S})$-norephedrine, $(1 \mathrm{~S}, 2 \mathrm{~S})$ $\mathrm{N}$-methylpseudoephedrine, and (1R, 2S)-N-methylephedrine in the Ephedra stems. ${ }^{6,12,13}$ Although all parts of the ephedra plant contain ephedrine alkaloids, the stem contains the highest comparative concentration, up to $3 \%$ of dry weight. ${ }^{13}$ Moreover,

Cite this article: Alsaeed W, Al Dhamen M, Ahmad R, Ahmad N, Naqvi AA. Clinical uses and toxicity of Ephedra sinica: An evidence-based comprehensive retrospective review (2004-2017). Pharmacog J. 2019;11(2):439-44. 
according to the Japanese and Chinese Pharmacopeia, all the products, i.e., "Ephedra Herb" are extracted from the dried stems of ES, Ephedra equisetina, or Ephedra intermedia. ${ }^{14}$ In the ancient times, ES was used due to its alkaloid constituents for treating respiratory, central nervous, and cardiovascular diseases, as it contains about $0.7 \%-0.8 \%$ of alkaloids in the whole plant. In addition, some of the Ephedra species contain high amounts of proanthocyanidins with prominent biological activities as like alkaloids, such as bronchodilation and vasorelaxation. Proanthocyanidin oligomers too have a comparatively significant effect over alkaloids, including antimicrobial, antioxidant, anti-inflammatory, immunosuppressive, antiviral, anti-invasive, antiangiogenic, antitumor, and cytotoxic activity, especially against the cancer cell lines such as SGC-7901, HepG2, and HeLa. ${ }^{6}$ Recently, ES has been introduced into the United States (US) market as a supplement for weight loss and energy gain, and toxicity cases up to $31 \%$ have been reported, associated with the use of products or supplements containing ephedra alkaloids. ${ }^{15}$ Many herbal medications have been reported with such forms of toxicities associated with the use of herbal products in any of its form and so is the dilemma with ES plant. Some of the toxicities observed for this plant are reversible that can be overcome and normalized by treatment whereas others may lead to irreversible toxicity or death in some cases. Research studies report the use of ES plant with possible complications in cardiac such as rapid ventricular contraction and atrial fibrillation, liver such as hepatitis and cirrhosis as well as at kidney level. ${ }^{16,17}$

This study aims to collect the data regarding the clinical cases observed from 2004 to 2017 and evaluate and observe them to find the association between clinical use and toxicity or adverse effects observed for ES. The study helps the health-care providers to have a glance over the main reason for toxicity, adverse effect, or deaths if reported, with the use of ES plant and to comprehend its therapeutic importance as compared to toxicity.

\section{MATERIALS AND METHODS}

\section{Databases and journals searched}

Databases included in this study were PubMed, Research gate, Science Direct, Google Scholar, and Thomson Reuters. Journals searched in this article were Journal of Ethnopharmacology, Frontiers in Ethno pharmacology, Intercultural Ethnopharmacology, Hindawi Journals, SAGE journals, and Central library Imam Abdulrahman Bin Faisal University.

\section{Keywords searched}

"Ephedra Sinica," "E. Sinica poisoning," "Ma-hung major active constituents," "E. Sinica uses and toxicity," "Ephedra sinica toxicity and its treatment," "Ma-hung toxicity cases in humans," "E. sinica toxicity cases in humans," clinical trials reported, adverse effects observed for E. sinica.

\section{Review period}

The article is a review with a retrospective period of 14 years, i.e., 2004-2017, where the articles regarding the clinical cases reported for ES in humans were collected from all databases.

\section{Inclusion criteria}

Any clinical case related to the use of ES as well as any adverse effects, poisoning, and death reported due to its use were included in the study. The cases reported in humans only, irrespective of age, gender, and nationality were considered for the study. In addition, the cases resulted due to an overdose of ES or its concomitant use with any conventional medication and lack of medical supervision, resulting in poisoning, were included in the study. Articles from all databases, irrespective of indexed or nonindexed journals, were downloaded.

\section{Exclusion criteria}

The clinical cases reporting minor or less severe side effects or adverse effects were excluded from the study. Similarly, any clinical case reported in animals or research study conducted in animals resulting a toxicity or death was not included in this study. In addition, in vitro studies and unapproved or human studies with lack of ethical approval were excluded from this study and is presented in Table 1.

\section{Search results}

Following the predefined inclusion and exclusion criteria, the literature was filtered, and 11 cases were found to meet the eligibility criteria.

\section{LITERATURE REVIEW}

The selected and eligible cases are explained year wise as below:

\section{Clinical case in 2017}

\section{Ephedra-containing product causes closed-angle glaucoma}

A 52-year-old female used a herbal product containing ephedra to increase weight loss. Few days later, she came to the emergency section complaining of nausea, vomiting, and headache accompanied with decreased visual acuity. The patient was diagnosed with bilateral angleclosure glaucoma and immediately treated with dorzolamide-timolol, brimonidine, and intravenous $20 \%$ mannitol. The patient was advised to stop the product, and the status improved following the complete treatment. ${ }^{18}$

\section{Clinical case in 2016}

\section{Ephedra sinica long use developed renal diseases}

A patient was admitted with a complaint, consisting of nephrolithiasis and renal dysfunction. On investigation, it was found that he was previously administered with ES at a dose of $40-3000 \mathrm{mg} /$ day for several months. This long-term treatment resulted in complications where no treatment was made available. ${ }^{19}$

\section{Clinical case in 2015}

\section{The relation between energy-weight loss product and cardiac problems}

In the US, the Regional Poison Centers made a study that showed limitation in toxicity of ES using Food and Drug Administration (FDA) ban from 2001 to 2013. The Poison Centers reported a total of 10,326 cases related to ES poisoning in 2002. This figure continued to decrease gradually down to 180 toward the end of 2013. By 2004, FDA ban has revealed to be useful in reducing the side effects of ES related to cardiac toxicity. ${ }^{20}$

\section{Clinical case in 2014}

Liver toxicities related to herbal product containing ephedra

Six patients from the US were using herbal medications, i.e., Ma-huang whereby they experienced an acute hepatitis. One among the patients had chronic HBV infection and two patients developed an acute liver failure; however, one of them was treated with liver transplant. ${ }^{2}$

\section{Clinical case in 2012}

Drug-herb interaction causes irreversible neurodegenerative disorder

A 29-year-old male has been injected with an intravenous mixture of pseudoephedrine (extracted from ephedra), potassium permanganate, and acetylsalicylic acid two to three times a day for 9 years and a half. Throughout these years, the patient developed many symptoms including speech disturbance, inability to walk independently, postural instability, tremor, and dystonia. The patient was diagnosed with manganese toxicity which leads to irreversible neurodegenerative disorder due to the long exposure to ES. He used to take fluoxetine, amitriptyline, diazepam, and 


\begin{tabular}{|c|c|c|c|c|c|c|}
\hline $\begin{array}{c}\text { Case } \\
\text { number }\end{array}$ & Form of ephedra used & Age & Gender & Clinical manifestation & Treatment protocol & Reason for use \\
\hline \multirow[t]{4}{*}{1} & Medication & 52 & Female & Nausea & Dorzolamide + timolol & To lose weight \\
\hline & & & & Vomiting & Brimonidine & \\
\hline & & & & Headache & Mannitol (20\% IV) & \\
\hline & & & & Decreased visual acuity & Stop the medication & \\
\hline \multirow[t]{2}{*}{2} & & - & Male & Nephrolithiasis & - & - \\
\hline & & & & Renal dysfunction & & \\
\hline \multirow[t]{5}{*}{3} & & - & Male and & Cardiac dysrhythmias & Standard therapy & To induce energy and to \\
\hline & & & female & Stroke & & lose weight \\
\hline & & & & Seizure & & \\
\hline & & & & Hypertension & & \\
\hline & & & & Death & & \\
\hline 4 & & - & - & $\begin{array}{c}\text { Acute hepatitis/chronic HBV } \\
\text { infection/liver failure }\end{array}$ & Liver transplant & - \\
\hline \multirow[t]{5}{*}{5} & Ephedra (IV)+other drugs & 29 & Male & Speech disturbance & Fluoxetine & - \\
\hline & & & & Inability to walk & Amitriptyline & \\
\hline & & & & Postural instability & Diazepam & \\
\hline & & & & Tremor & L-Dopa & \\
\hline & & & & Dystonia & & \\
\hline \multirow[t]{4}{*}{6} & - & 17 & Male & Jaundice & Cholestyramine & For physical performance \\
\hline & & & & Hyperbilirubinemia & Ursodeoxycholic acid & \\
\hline & & & & Elevated aminotransferases & Stop the medication & \\
\hline & & & & Hepatomegaly & & \\
\hline 7 & Medication/placebo & $20-30$ & $\begin{array}{l}\text { Females } \\
\text { and males }\end{array}$ & $\begin{array}{l}\text { Imbalance on the autonomic } \\
\text { nervous system }\end{array}$ & - & $\begin{array}{l}\text { To evaluate the effect } \\
\text { of ephedra on the } \\
\text { autonomic nervous } \\
\text { system }\end{array}$ \\
\hline \multirow[t]{3}{*}{8} & Medication & 21 & - & Complete muscle failure & Fluid-containing bicarbonate & To improve physical \\
\hline & & & & Hypotensive & & performance \\
\hline & & & & Tachycardia & & \\
\hline 9 & $\begin{array}{l}\text { Dietary supplement/ } \\
\text { medication }\end{array}$ & - & - & Cardiovascular toxicity & Stop the supplement & $\begin{array}{l}\text { To improve performance } \\
\text { and lose weight }\end{array}$ \\
\hline \multirow[t]{4}{*}{10} & - & 45 & Females & Cardiac collapse & - & - \\
\hline & & & & Severe headache & & \\
\hline & & & & Vomiting & & \\
\hline & & & & Loss of awareness & & \\
\hline \multirow[t]{2}{*}{11} & - & 19 & Male & Chest pain & Medication for heart failure & - \\
\hline & & & & Breathing difficulty & & \\
\hline
\end{tabular}

IV=Intravenous, $\mathrm{HBV}=$ Hepatitis B virus

L-Dopa to recover from this toxicity; however, no improvement was observed even after 2 years of treatment. ${ }^{21}$

\section{Energy supplement-induced liver injuries}

A 17-year-old student from Guerrero, Mexico, was using energy supplements and natural product to enhance physical performance. Subsequently, he developed acute mixed liver injury with other symptoms including jaundice, hyperbilirubinemia, elevated aminotransferases, and apparent hepatomegaly, after taking a lot of these supplements. His liver test returned to normal after a treatment with cholestyramine and ursodeoxycholic acid. ${ }^{22}$

\section{Clinical case in 2010}

Autonomic nervous system imbalance caused by Ephedra sinica extract Twenty healthy adults (10 females and 10 males) participated in a study of the effects of ES on autonomic nervous system (given either $1 \mathrm{~g}$ of
ES dry extract or a placebo). The treatment was taken once a day for 2 weeks with 1 week in between as a washout period. Heart Rate Variability analysis, to evaluate the results of the medical trial, revealed both acute and chronic effects on the autonomic nervous system balance. The effects may be due to an increase in the sympathetic nervous system activity and decrease in the parasympathetic activity. There is no specific treatment for this toxicity. ${ }^{23}$

\section{Clinical case in 2006 Cardiovascular problems due to herbal supplement}

A 21-year-old healthy adult was using herbal supplement containing ES to enhance the performance; however, the patient was found to have complete muscle failure. Before the use of ES, the patient had hypotension and tachycardia which progressed to acute renal failure with the elevation of creatine kinase ( $426 \mathrm{U} / \mathrm{L}$ to $241.418 \mathrm{U} / \mathrm{L}$ in 6 days). A treatment with 
fluids containing bicarbonate for 1 month recovered the renal function and creatine kinase to normal; however, the muscle biopsy was negative for underlying neuromuscular disease. ${ }^{24}$

\section{Clinical case in 2005}

\section{Cardiovascular toxicity among athletes using ephedrine supplement}

Athletes in the US developed cardiovascular toxicity with the use of drugs and dietary supplements containing ES to improve athletic performance and loss weight. No specific treatment for such toxicity was reported except to stop the use of drug. ${ }^{25}$

\section{Death due to myocardium degeneration after using ephedra product}

A 45-year-old female using ES died due of cardiac collapse. Initially, she had a complaint of severe headache and used painkiller (aspirin). After a short time, she was suffering from vomiting and loss of awareness. The medical history revealed a degenerative myocardium such as lipofuscin associated with caspase activation, myocyte apoptosis, and extensive cleavage of myofibrillar proteins ( $\alpha$-actinin, $\alpha$-actin, and cardiac troponin-T), associated with the use of ES. ${ }^{26}$

\section{Clinical case in 2004}

\section{Adverse reaction leading to death}

A 19-year-old patient was admitted to the emergency department with major complaint of intermittent chest pain extending to the left arms with breathing difficulty. Left heart catheterization revealed a significant coronary artery disease, global hypokinesis, and dilated left ventricle. Following some standard therapies for heart failure, the patient was discharged; however, a death was reported for the patient after 5 weeks. An objective causality assessment probability scale disclosed the use of ES in the same patient, whereby cardiomyopathy was resulted as an adverse reaction to ephedra use. ${ }^{27}$

\section{DISCUSSION}

ES, known as Chinese Ma-hang, is a part of traditional Chinese medicine (TCM) used for many conditions due to its alkaloid content. The plant is used mainly for the treatment of central nervous, cardiovascular, and respiratory system diseases. For ES, an increase in use (18\% to $32 \%)$ has been observed particularly in two groups, i.e., athletes and cancer patient. In the US, it has been estimated that people spend around 30 million dollars for weight loss products without seeking medical advice, among which few products are allowed by FDA without verifying their safety and efficacy. ${ }^{22}$ Usually, traditional drugs commonly used as energy supplement resulted in nephrotoxicity, liver injuries, and extreme release of catecholamine in the form of dopamine, epinephrine, pseudoephedrine, and norepinephrine. ${ }^{28}$ As per the literature reports, these conditions are caused by using some known materials such as usnic acid, Ma-huang (ES), anabolic steroids, Morinda citrifolia (Noni Juice), Hydroxycut, kava, Vitamin A, Germander, and Camellia sinensis (green tea). The toxicity may take place by different mechanisms such as hypersensitivity reaction, autoimmunity, accumulation of toxic metabolite, and drugs interaction. ${ }^{22,29}$

ES as a medicinal product, though, has more widespread uses; however, it may induce many adverse effects besides its therapeutic purpose. This literature review highlights the therapeutic uses for ES along with the adverse effects or toxicity associated with its use and extracts out the causes and reasons leading to such unwanted conditions. This will enable the end user to keep in mind the comparative value of ES in treating a particular disease. Following an in-depth literature search, we found the following undesired effects resulting with the use of ES.

\section{Effect on sympathetic nervous system and toxicity}

ES stimulates the sympathetic nervous system that may lead to cardiovascular toxicity and convulsions. ${ }^{30}$ The vasoconstriction effect, following oral or local administration of ES, significantly increases the blood pressure and vasospasm which may progress toward hypertensive crisis as well as several neurological manifestations. These neurological symptoms happen in the absence of any relevant history. ${ }^{31}$

\section{Toxic effect on the heart}

ES acts as epinephrine-like substance and stimulates the heart. It has been confirmed that ephedra can increase blood pressure and stress the circulation which leads to serious conditions such as stroke, infarction, and other heart complications. ${ }^{32}$

\section{Ephedra sinica affects surgical outcomes}

Dietary supplements or products containing ephedra used by some patients may react or interact with surgical medications, hence inducing some unexpected complications. The serious undesired reactions happened during or after surgery related to these supplements include bleeding, poor wound healing, prolonged sedation, photosensitivity reaction, and arrhythmias. Thus, it is advised to stop any ephedra-containing dietary supplements, at least 7 days before diagnostic or surgical procedures. ${ }^{33}$

\section{Fat-burning product produces life-threatening consequence}

ES stimulates the sympathetic nervous system and pushes the body into a fight or flight mode. This adrenaline-like effect increases heart rate and blood pressure and stimulates lipolysis; thus, it makes the body to burn more calories. Various fat-burning supplement contains ephedra in combination with caffeine to potentiate its effect; however, the adverse reactions posed from these products are life threatening such as brain hemorrhage, seizures, chest pain, tremor stroke, and possibly death. ${ }^{34}$

\section{Liver toxicity}

The use of products containing ephedra may develop health issues. Few of the user have reported liver problems such as chronic hepatitis B infection and acute liver failure which required a transplant in a few cases. ${ }^{2}$

Herein, we mentioned 11 different cases in our study which reported toxicities associated with the use of ES. Few of the cases mentioned liver toxicity whereas others reported cardiac problems and hypertension along with neurological problems. However, it is noteworthy to mention here that after an in-depth study of the reported cases for the possible reasons of toxicity, we ended with a conclusion that the toxicity resulted due to drug interaction, i.e., a concomitant use of ES with conventional medications, long-term use of ES plant in a particular disease, overdose, misuse of ES, i.e., as an energy source or supplement to enhance performance, use of the plant with lack of proper medical supervision, and lack of knowledge about its complications. Moreover, lack of proper regulation from FDA also adds to the disadvantages as they are easily available in the form of over-the-counter drugs and supplements at any drug store which makes it easily accessible to end user. Thus, to claim ES as a toxic plant is not justifiable at this stage.

Moreover, the use of ES plant with proper dose and in specific conditions as directed along with use under proper medical supervision provides more advantages and therapeutic effects as discussed in the forthcoming section.

\section{Ephedra sinica used for nasal congestion}

ES contains ephedrine and pseudoephedrine, the two oldest agents known for their efficacy in nasal congestion. Pseudoephedrine is used 
orally alone or in combination with other drugs such as antihistamine $\left(\mathrm{H}_{1}\right)$ to treat allergies and common cold. On the other hand, ephedrine applied to the nasal mucosa reduces nasal congestion more strongly and quickly than oral pseudoephedrine but with a short duration of action. ${ }^{31}$

\section{Bronchodilator effect of Ephedra sinica}

Ephedrine is a crude powdered extract from the stem of ES, used in TCM for over 5000 years to treat asthma. Ephedrine has an adrenalinelike effect on the nervous system, and its benefits in asthmatic patients are achieved through the activation of $\mathrm{B}_{2}$ receptor found on the smooth muscle of the airways which is responsible of relaxation effect. ${ }^{35}$

\section{Anti-inflammatory and immunosuppressive properties}

Polysaccharide, purified from the stems of ES, is considered to be an important contributor to immunosuppressive and anti-inflammatory effects in the plant. The most effective polysaccharide is ESP-B4 which shows activity against cytokines (monocyte chemoattractant protein-1, tumor necrosis factor- $\alpha$, and interleukin-6 [IL-6], IL-1 $\beta$, and IL-8) and inflammatory mediators (prostaglandin E2), and within the serum, it is suggested that ESP-B4 is effective to treat adjuvant-induced arthritis. ${ }^{36}$

\section{Nutritional value of Ephedra sinica}

In addition to the above medical uses, Chinese people used ES fruit part as a food (eaten dried or fresh, raw or cooked) and consumed safely through different ways, such as in cheese condiment, tea substitute, and refined sugar. The nutritional components responsible in fruit are carbohydrate, protein, fibers, fatty acids, and mineral. However, there are only a few reports related to the fruit, and it has been stated that the fruit part of ES is nontoxic for birds or rodent even. ${ }^{37}$

The discussion provides an insight regarding the comparative value of ES. It is evident from the mentioned clinical cases and literature reports that ES may have adverse effects or toxicity, leading to deaths in extreme cases even. However, it was observed that long-term use, overdose, misuse, ES, and conventional drug interactions, as well as lack of medical supervision for ES in a particular treatment are the factors which favor such unwanted effects. On the other hand, the number of reported cases during the last 14 years, i.e., 11, is not a sufficient explanatory proof to rule out ES for being used in the treatment of various specified disease. Furthermore, the untoward effects are very less for ES as compared to its beneficial effects in different treatment and conditions.

\section{CONCLUSION}

ES may lead to serious side effects, including cardiac, renal, and liver complications. However, a proper use of the plant with suggested dose, frequency, and duration, under a proper monitoring and medical supervision, may avoid such complications and may result in the utilization of ES for an effective therapeutic plan.

\section{Financial support and sponsorship}

Nil.

\section{CONFLICTS OF INTEREST}

There are no conflicts of interest.

\section{REFERENCES}

1. Pal D, Sahu CK, Haldar A. Bhasma : The ancient indian nanomedicine. J Adv Pharm Technol Res 2014;5:4-12.

2. Teschke R. Traditional Chinese Medicine Induced Liver Injury. J Clin Transl Hepatol. 2014; 2(2): 80-94.

3. Steven D, Ehrlich NM. Solutions Acupuncture, a Private Practice Specializing in Complementary and Alternative Medicine. Phoenix, AZ: VeriMed Healthcare Network; 2015.
4. Zhou R, Luo F, Lei H, Zhang K, Liu J, He H, et al. Liujunzi tang, a famous traditional Chinese medicine, ameliorates cigarette smoke-induced mouse model of COPD. J Ethnopharmacol 2016;193:643-51.

5. Jetti R, Raghuveer CV, Mallikarjuna RC. Protective effect of ascorbic acid and Ginkgo biloba against learning and memory deficits caused by fluoride. Toxicol Ind Health 2016:32:183-7.

6. Orejola J, Matsuo Y, Saito Y, Tanaka T. Characterization of proanthocyanidin oligomers of Ephedra sinica. Molecules 2017;22. pii: E1308.

7. Upadhyay A, Tuenter E, Ahmad R, Amin A, Exarchou V, Apers S, et al. Kavalactones, a novel class of protein glycation and lipid peroxidation inhibitors. Planta Med 2014;80:1001-8.

8. Ahmad R, Upadhyay A, Ahmad M, Pieters L. Antioxidant, antliglycation and antimicrobial activities of Ziziphus oxyphylla and Cedrela serrata extracts. Eur J Med Plants 2013;3:520-9.

9. Zheng $F H$, Wei $P$, Huo $H L$, Xing XF, Chen FL, Tan XM, et al. Neuroprotective effect of gui zhi (ramulus cinnamomi) on ma huang- (herb ephedra-) induced toxicity in rats treated with a ma huang-gui zhi herb pair. Evid Based Complement Alternat Med 2015;2015:913461.

10. Abourashed EA, El-Alfy AT, Khan IA, Walker L. Ephedra in perspective - a current review. Phytother Res 2003;17:703-12.

11. Kim BS, Song MY, Kim H. The anti-obesity effect of Ephedra sinica through modulation of gut microbiota in obese Korean women. J Ethnopharmacol 2014;152:532-9.

12. Ibragic S, Sofic E. Chemical composition of various Ephedra species. Bosn J Basic Med Sci 2015;15:21-7.

13. Kilpatrick K, Pajak A, Hagel JM, Sumarah MW, Lewinsohn E, Facchini PJ, et al. Characterization of aromatic aminotransferases from Ephedra sinica stapf Amino Acids 2016;48:1209-20.

14. Zang $X$, Shang M, Xu F, Liang J, Wang X, Mikage M, et al. A-type proanthocyanidins from the stems of Ephedra sinica (Ephedraceae) and their antimicrobial activities. Molecules 2013:18:5172-89.

15. Haller CA, Benowitz NL. Adverse cardiovascular and central nervous system events associated with dietary supplements containing Ephedra alkaloids. N Engl J Med 2000;343:1833-8.

16. Scopolamine overdose: Various toxicities following transdermal administration case report. React Wkly 2014;1485:33.

17. Digoxin toxicity and high digoxin level: Case report. React Wkly 2015;1533:177.

18. Ryu SJ, Shin YU, Kang MH, Cho HY, Seong M. Bilateral acute myopia and angle closure glaucoma induced by ma-huang (Ephedra): A case report. Medicine (Baltimore) 2017;96:e9257.

19. Nauffal M, Gabardi S. Nephrotoxicity of natural products. Blood Purif 2016:41:123-9.

20. Zell-Kanter M, Quigley MA, Leikin JB. Reduction in Ephedra poisonings afte FDA ban. N Engl J Med 2015;372:2172-4.

21. Koksal A, Baybas S, Sozmen V, Koksal NS, AltunkaynakY, Dirican A, et al. Chronic manganese toxicity due to substance abuse in Turkish patients. Neurol India 2012;60:224-7.

22. Avelar-Escobar G, Méndez-Navarro J, Ortiz-Olvera NX, Castellanos G, Ramos R, Gallardo-Cabrera VE, et al. Hepatotoxicity associated with dietary energy supplements: Use and abuse by young athletes. Ann Hepatol 2012;11:564-9.

23. Chen WL, Tsai TH, Yang CC, Kuo TB. Effects of Ephedra on autonomic nervous modulation in healthy young adults. J Ethnopharmacol 2010;130:563-8.

24. Stahl CE, Borlongan CV, Szerlip M, Szerlip H. No pain, no gain - exerciseinduced rhabdomyolysis associated with the performance enhancer herbal supplement Ephedra. Med Sci Monit 2006;12:CS81-4.

25. Dhar R, Stout CW, Link MS, Homoud MK, Weinstock J, Estes NA $3^{\text {rd }}$, et al. Cardiovascular toxicities of performance-enhancing substances in sports. Mayo Clin Proc 2005;80:1307-15.

26. Chen-Scarabelli C, Hughes SE, Landon G, Rowley P, Allebban Z, Lawson N, et al. A case of fatal Ephedra intake associated with lipofuscin accumulation, caspase activation and cleavage of myofibrillary proteins. Eur $\mathrm{J}$ Heart Fail 2005; 7:927-30.

27. Naik SD, Freudenberger RS. Ephedra-associated cardiomyopathy. Ann Pharmacother 2004;38:400-3.

28. Solanki P, Yadav P, Kantharia N. Ephedrine: Direct, indirect or mixed acting sympathomimetic. Int J Basic Clin Pharmacol 2014;3:431-6.

29. Rahman N, Ahmad M, Riaz M, Mehjabeen, Jahan N, Ahmad R, et al. Phytochemical, antimicrobial, insecticidal and brine shrimp lethality bioassay of the crude methanolic extract of Ajuga parviflora benth. Pak J Pharm Sci 2013;26:751-6.

30. Ephedra sinica. American Association for Clinical Chemistry. Available from: https://www.aacc.org/community/divisions/tdm-and-toxicology/toxin-library/ ephedra-sinica. Last accessed on; 23rd July, 2018.

31. Laccourreye O, Werner A, Giroud JP, Couloigner V, Bonfils P, Bondon-Guitton E, et al. Benefits, limits and danger of ephedrine and pseudoephedrine as nasal decongestants. Eur Ann Otorhinolaryngol Head Neck Dis 2015;132:31-4.

32. Cockey CD. Ephedra Banned: Consumers Advised to Stop Using Ephedra Products Immediately. AWHONN Lifelines. 2004; 8(1):19-21. 
33. Ciocon JO, Ciocon DG, Galindo DJ. Dietary supplements in primary care. Botanicals can affect surgical outcomes and follow-up. Geriatrics 2004;59:20-4.

34. Don't get burned by fat burner supplements. Tufts University Health and Nutrition Letter. ProQuest 2002;20:SI.

35. Alcibey A. Dual bronchodilator therapy: A review. Clin Res Trial 2017;3:1-12.
36. Wang Q, Shu Z, Xing N, Xu B, Wang C, Sun G, et al. A pure polysaccharide from Ephedra sinica treating on arthritis and inhibiting cytokines expression. Int J Biol Macromol 2016;86:177-88.

37. Khasbagan S. Ephedra sinica stapf (Ephedraceae): The fleshy bracts of seed cones used in Mongolian food and its nutritional components. Econ Bot 2007;61:192-7.

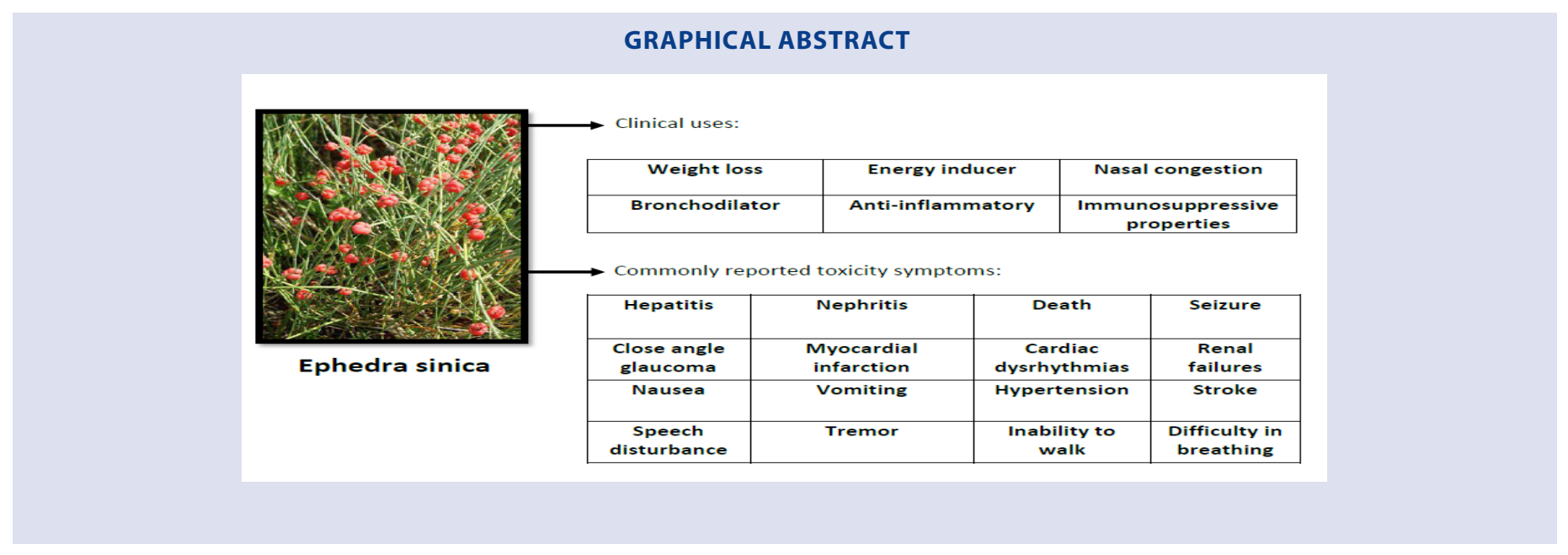

Cite this article: Alsaeed W, Al Dhamen M, Ahmad R, Ahmad N, Naqvi AA. Clinical uses and toxicity of Ephedra sinica: An evidencebased comprehensive retrospective review (2004-2017). Pharmacog J. 2019;11(2):439-44. 